\title{
Role of Endoscopy in Primary Sclerosing Cholangitis
}

\author{
Purnima Bhat ${ }^{1,2}$ and Lars Aabakken ${ }^{3,4}$ \\ ${ }^{1}$ Gastroenterology and Hepatology Unit, Canberra Hospital, Canberra, Australia, ${ }^{2}$ College of Health and Medicine, Australian National \\ University, Canberra, Australia, ${ }^{3}$ Department of Transplantation Medicine, Oslo University Hospital, Oslo, Norway, ${ }^{4}$ Faculty of Medicine, \\ University of Oslo, Oslo, Norway
}

Primary sclerosing cholangitis (PSC) is a progressive disease of the bile ducts that usually results in chronic liver disease often requiring liver transplantation. Endoscopy remains crucial to the care of these patients, although magnetic resonance cholangiopancreatography has replaced endoscopic retrograde cholangiopancreatography (ERCP) as the primary imaging modality for diagnosis. For detection of dysplasia or cholangiocarcinoma, ERCP with intraductal sampling remains compulsory. Moreover, dominant strictures play an important part in the disease development, and management by balloon dilatation or stenting could contribute to long-term prognosis. In addition, endoscopy offers management for adverse events such as bile leaks and anastomotic strictures after liver transplantation. Finally, the special phenotype of inflammatory bowel disease associated with PSC as well as the frequent occurrence of portal hypertension mandates close follow-up with colonoscopy and upper endoscopy. With the emergence of novel techniques, the endoscopist remains a key member of the multidisciplinary team caring for PSC patients. Clin Endosc 2021;54:193-201

Keywords: Cholangiocarcinoma; Endoscopic retrograde cholangiopancreatography; Endoscopy; Primary sclerosing cholangitis

\section{INTRODUCTION}

Primary sclerosing cholangitis (PSC) is a disease of the biliary tree, of multimodal etiology, that is usually progressive and results in chronic liver disease. ${ }^{1}$ The prevalence of the disease varies substantially across the globe, but in some regions, including Scandinavia, it is among the one of the most frequent indications for liver transplantation. ${ }^{2,3}$

No medical therapy has been consistently shown to be helpful in delaying disease progression or reducing the frequency or severity of biliary obstruction. Repeat endoscopic interventions are often part of the care, primarily to offer limited

Received: January 7, 2020 Revised: March 23, 2020

Accepted: March 23, 2020

Correspondence: Lars Aabakken

Department of Transplantation Medicine, Oslo University Hospital, Sognsvannsveien 20 , Oslo 0027 , Norway

Tel: +47-23072400, Fax: +47-23072410, E-mail: lars.aabakken@medisin.uio.no ORCID: https://orcid.org/0000-0002-3622-3826

(c) This is an Open Access article distributed under the terms of the Creative Commons Attribution Non-Commercial License (http://creativecommons.org/ licenses/by-nc/3.0) which permits unrestricted non-commercial use, distribution, and reproduction in any medium, provided the original work is properly cited. treatment of obstructed ducts that cause recurrent cholangitis or jaundice with intolerable itching. The role of endoscopic retrograde cholangiopancreatography (ERCP) has shown promise in delaying progress of the disease by offering repeat therapeutic interventions. However, the most sinister concern is a 400 -fold increase in the risk of cholangiocarcinoma (CCA) compared to the average population, often diagnosed early in the course of the disease. ${ }^{4}$ Thus, intraductal sampling is a key element in surveillance and detection, offering a role for ERCP not replaceable by cross sectional imaging.

Finally, although liver transplantation is an effective therapy in PSC patients, postoperative issues do occur, many of which are remediable by endoscopic interventions, obviating repeat surgery.

Hence, while imaging technology keeps improving, there remains a role for interventional endoscopy in the care of these patients, for therapy, and for intraductal sampling. In this review, we attempt to delineate the role for diagnostic and therapeutic endoscopy in the care of PSC patients, including the role of endoscopy for surveillance and therapy of upper gastrointestinal (GI) and colonic complications. 


\section{DIAGNOSIS OF PSC}

PSC is most often diagnosed during surveillance of liver function tests in subjects (particularly young males) with ulcerative colitis. Less frequently, patients may present with suggestive symptoms, particularly itching and/or jaundice and fatigue. ${ }^{5}$ In this setting, abdominal ultrasound is often performed, but subsequent magnetic resonance cholangiopancreatography (MRCP) is usually indicated to detect and better delineate bile duct changes.

The typical radiological findings of PSC include multiple short strictures of intra- and/or extrahepatic bile ducts causing a bead-like appearance (Fig. 1). The utility of MRCP assessment in disease prognostication at diagnosis is promising. ${ }^{6,7}$ With typical MRCP findings, additional imaging measures for the diagnosis of PSC are rarely needed, although mimicking conditions resulting in secondary sclerosing cholangitis may need to be excluded (Table 1).

Comparative studies have shown MRCP to be comparable to ERCP in the primary diagnosis of PSC and is generally sufficient. ${ }^{8,9}$ ERCP is only required in very select cases for imaging and diagnosis. If the index of suspicion is high but the MRCP is inconclusive, or is contraindicated, ERCP may add accuracy to the ductal delineation, although liver biopsy may offer better assessment of parenchymal and small duct disease. Moreover, MRCP is sometimes suboptimal, due to technical challenges, lack of expertise, or artefacts, some of which may be sufficiently addressed by repeating the MRCP or utilizing a better quality instrument such as 3 Tesla magnetic resonance

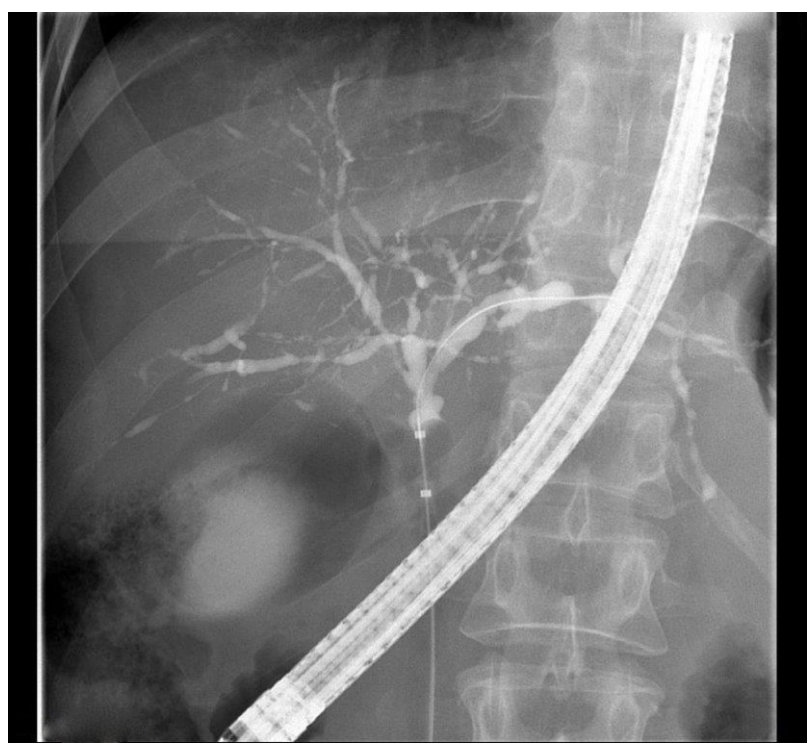

Fig. 1. Typical cholangiographic presentation of primary sclerosing cholangitis with multiple short strictures and dilatations that give the intrahepatic ducts a "bead-like" appearance. Note the balloon occlusion for optimal ductal imaging. imaging. ${ }^{10}$ Finally, the occasional patient may not be able to undergo MRCP due to claustrophobia or the presence of metallic implants. In these select cases, ERCP should be considered to establish the diagnosis, given the important long-term consequences for the patient.

Secondary sclerosing cholangitis may be indistinguishable from PSC radiologically, and prove to be a diagnostic challenge (Table 1). In these cases, clinical history and other adjunctive diagnostic modalities, including serology or liver biopsy, may be helpful. ERCP rarely adds to the diagnostic matrix in these cases, but the distinction toward alternative explanations of the biliary changes is obviously important since the prognosis as well as the therapeutic options will be quite different. In addition, the concern of subsequent development of CCA appears to be limited to the PSC patients as none of the other conditions have been shown to be associated with cancer development.

In small duct PSC the ducts are macroscopically normal, so the diagnosis, by definition, is not picked up by MRCP or ERCP, but rather by liver biopsy when the index of suspicion is high. Some of these patients will later develop classic PSC ductal changes, particularly those with the concomitant inflammatory bowel disease (IBD) phenotype. ${ }^{11}$

Thus, while ERCP may be of importance to diagnose concomitant disease or complications related to PSC (stones, casts, CCA, postoperative complications), its role in primary diagnostics and differential diagnoses is limited.

\section{SURVEILLANCE OF PSC}

Development of CCA is a major concern in PSC patients, with a lifetime risk of $10 \%-20 \%{ }^{4}$ Up to $50 \%$ of CCA develop in the first year of the diagnosis of PSC. ${ }^{12}$ Compared to an age-adjusted normal population, the risk is 400 -fold increase in PSC patients. ${ }^{4}$ PSC patients are also at an increased risk of gallbladder malignancies and hepatocellular cancer. ${ }^{13}$

The use of ERCP primarily for CCA surveillance purposes is controversial and is not routinely offered in most centers. Rather, most centers rely on a combination of regular assessment with clinical status, non-interventional imaging, liver biochemistry, and serum CA-19-9 levels, as outlined in current guidelines. ${ }^{14}$ The success of this strategy in the early detection of CCA is poor, but the expense and risk of regular ERCP in asymptomatic patients precludes its use as a surveillance tool. Usually, clinical and/or biochemical deterioration leads to MRCP which may or may not show a worsening of ductal changes. Conversely, the presence of ductal disease, even severe disease, by MRCP in the absence of clinical and biochemical changes is typically an insufficient indication for en- 
Table 1. Primary Sclerosing Cholangitis and Other Conditions with Similar Cholangiographic Findings (Adapted from European Society of Gastrointestinal Endoscopy ${ }^{9}$ )

\begin{tabular}{|c|c|c|}
\hline Diagnosis & Cholangiographic features & Additional factors \\
\hline PSC & $\begin{array}{l}\text { Multifocal intra- and extrahepatic strictures "bead- } \\
\text { ed" appearance, diverticular outpouchings, diffuse } \\
\text { distribution }\end{array}$ & Male, young age debut, concomitant IBD \\
\hline Infectious/ascending cholangitis & $\begin{array}{l}\text { Multiple intrahepatic bile duct strictures, stones, } \\
\text { biliary abscesses }\end{array}$ & $\begin{array}{l}\text { Anatomic variants, previous EPT, hepaticojejunos- } \\
\text { tomy/duodenostomy }\end{array}$ \\
\hline Ischemic cholangitis & $\begin{array}{l}\text { Proximal intrahepatic bile duct strictures, bile duct } \\
\text { necrosis, bilomas, abscesses, biliary casts }\end{array}$ & $\begin{array}{l}\text { Hepatic surgery, vascular anastomoses, ischemic } \\
\text { disasters }\end{array}$ \\
\hline Caustic/toxic cholangitis & $\begin{array}{l}\text { Proximal regional intrahepatic bile duct strictures, } \\
\text { bile duct necrosis, biliomas, abscesses, biliary cast }\end{array}$ & $\begin{array}{l}\text { Topical chemotherapy, hydatid disease therapy, cyst } \\
\text { ablation injection therapy }\end{array}$ \\
\hline $\begin{array}{l}\text { Immunodeficiency-related } \\
\text { cholangitis }\end{array}$ & $\begin{array}{l}\text { Stricture of the distal common bile duct, papillitis, } \\
\text { acalculous cholecystitis }\end{array}$ & AIDS, CVID, other immunodeficiency \\
\hline IgG4-related cholangitis & $\begin{array}{l}\text { Multifocal central bile duct strictures, bile duct wall } \\
\text { thickening with visible lumen }\end{array}$ & $\begin{array}{l}\text { Autoimmune pancreatitis, sialadenitis, sclerosing } \\
\text { mesenteritis, IBD }\end{array}$ \\
\hline
\end{tabular}

AIDS, acquired immunodeficiency syndrome; CVID, common variable immunodeficiency; EPT, endoscopic papillotomy; IBD, inflammatory bowel disease; PSC, primary sclerosing cholangitis.

doscopic intervention; instead, it is the combination of ductal changes with clinical or biochemical worsening that mandates intervention. In addition to ERCP, other imaging, including computer tomography and positron emission tomography may be warranted to detect mass lesions, pathological lymph nodes, or other non-ductal pathology.

Thus, when ERCP is required in the investigation for possible CCA, it is primarily the combined utility of additional diagnostics, such as intraductal sampling and cholangioscopic assessment, that justifies the procedure, while contrast-based cholangiography rarely adds to the conclusions of a high-quality MRCP in this setting.

Intraductal sampling, typically of new or worsening strictures, has traditionally been based on brush cytology. This method is well established, usually easy to perform, and should be considered mandatory. However, the sensitivity for brush cytology alone is probably below $50 \%,{ }^{15}$ although better results have been reported recently. ${ }^{16}$ Novel ways to score cytological findings have been proposed that may increase sensitivity, ${ }^{17}$ but negative results mandate close monitoring and/or repeat sampling. However, the specificity of brush cytology is high and the finding of dysplastic cells has important prognostic significance. The dysplasia-carcinoma sequence is so well established in this population that referral for evaluation for transplantation based on dysplastic duct cytology alone prior to the development of CCA should be strongly considered. ${ }^{18,19}$

The addition of fluorescence in-situ hybridization (FISH) analysis of the brush material may add to the diagnostic value, but the final role of this quite labor-intensive technique is still undefined, and the added accuracy is probably moderate. ${ }^{20}$ Interestingly, in a study of serial FISH analyses in PSC patients, $>50 \%$ of positive FISH results reverted to normal in subsequent analyses, mandating caution in assessment based on positive FISH alone. ${ }^{21}$ Recently, 346 biliary brushings and biopsies were studied by gene sequencing with a CCA-specific panel, showing a sensitivity of $73 \%$, with $100 \%$ specificity for CCA. ${ }^{22}$

Other potential ancillary diagnostics derived from ERCP include biliary aspirate and fluoroscopy-guided transpapillary biopsies. The latter may be of value for the diagnosis of CCA in general, ${ }^{23}$ but the added value when brush cytology is also performed appears limited. ${ }^{24}$ In addition, it should be noted that the specific anatomy in PSC patients limits the applicability of transpapillary forceps biopsies markedly, allowing access to distal strictures only. Bile aspirate may add to the cytological assessment, although it is rarely sufficient to make a diagnosis of cancer; however, novel tumor marker characterization in aspirated bile holds some promise.

\section{Cholangioscopy}

Although endoluminal direct imaging of the bile ducts has been available for decades by so-called "mother-baby" dual endoscopy techniques, the cost, complexity, and fragility of the instruments have precluded mainstream application. The introduction of the single operator cholangioscope (SpyGlass ${ }^{\mathrm{TM}}$ Direct Visualization System [Boston Scientific, Marlborough, MA, USA]) has been a game-changing technology, ${ }^{25}$ particularly in its revised digital version, ${ }^{26}$ rapidly establishing a 

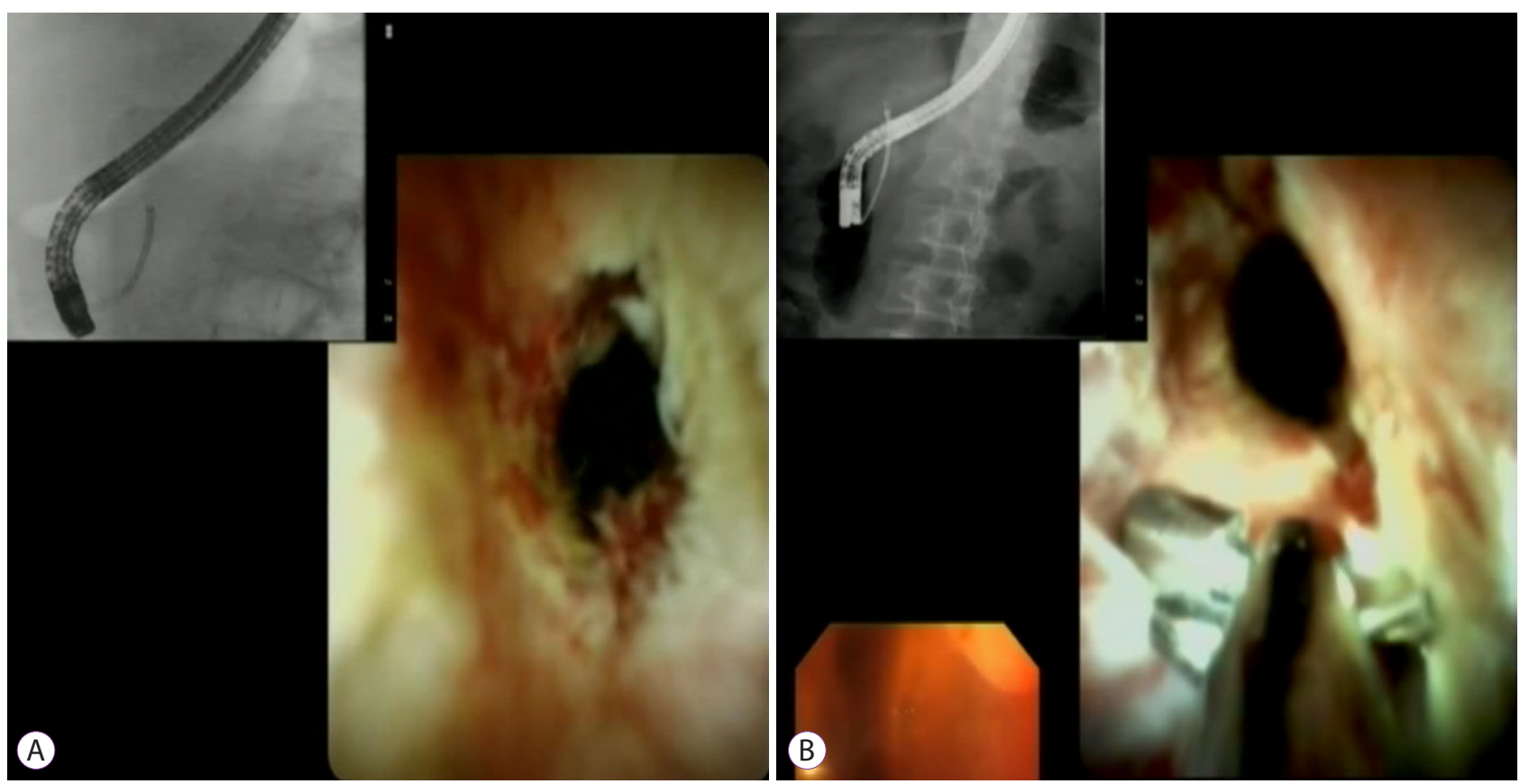

Fig. 2. (A) Cholangioscopic appearance of ductal changes suspicious of malignancy. (B) SpyBite ${ }^{\top \mathrm{M}}$ (Boston Scientific, Marlborough, MA, USA) biopsy sampling of suspicious stricture.

role in the negotiation of complex pancreatobiliary situations (Fig. 2A, B). Visual assessment as well as directed histology sampling with the minute SpyBite ${ }^{\mathrm{TM}}$ biopsy forceps (Boston Scientific) are promising techniques in the characterization of biliary strictures.

For PSC assessment specifically, the evidence is as yet limited. Most studies report biliary strictures in general, sometimes with a small subgroup of PSC patients, and again, the ductal aberrations with multiple narrow strictures limit the visualization as well as the navigation with the cholangioscope. However, the visualization of tiny ducts also facilitates wire access to otherwise difficult segments of the biliary tree.

Majeed and co-workers reported their extensive PSC material from Sweden, where sequential diagnostic modalities were applied..$^{27} \mathrm{~A}$ total of 209 transplanted PSC patients were assessed, and despite the selection bias of this inclusion, the explanted livers offered superb gold standard for the definite diagnosis. Single brushing had a sensitivity of $57 \%$ for either CCA or high-grade dysplasia, while the addition of FISH increased this to $84 \%$, repeated brushings to $82 \%$, and repeated brushings plus cholangioscopy, which would be the typical scenario, had a sensitivity of $100 \%$ in this study.

Looking at transplanted patients only may not tell the whole story. Indeed, in another recent report from the Mayo Clinic, Kaura et al. ${ }^{15}$ found an added utility of FISH and cholangioscopy, but with a combined sensitivity of only $69.2 \%$ and no added value of single-operator cholangioscopy-guided biopsies for the subgroup with PSC (36 of the 92 included patients).

Visual assessment of indeterminate strictures may also add to the diagnostic process and even more with newer generation cholangioscopes. At this stage, more experience and data are needed to accurately utilize this information, and for now, and parallel to other GI tract diagnostics, histological examination of tissue is still required. Fortunately, the current cholangioscope offers targeted biopsies of worrisome strictures rather than blind brushings. In a recent prospective trial of 61 patients, cholangioscopic assessment of indeterminate strictures significantly impacted the surgical decision-making regarding resection and transplantation. This was true even among the subgroup with PSC, despite a sensitivity of only $52 \%-63.6 \%$ of combined visualization and biopsy, likely due to the high specificity $(100 \%)$ and a relatively high negative predictive value (83.6\%). ${ }^{28}$ In another retrospective trial including 40 PSC patients, the sensitivity was $64 \%$, with a lower accuracy than brush cytology, and with a limited clinical impact (change of management in $17 \%$ of patients only). ${ }^{29}$ Fortunately, the SpyBite $^{\mathrm{TM}}$ forceps has been recently improved, and better sample quality is to be expected in the near future.

\section{Other ancillary techniques}

Endoscopic ultrasound (EUS) is well established for hepatobiliary diagnostics, and intraductal ultrasound (IDUS), confocal laser endomicroscopy (CLE), and optical coherence tomography (OCT) have been introduced for probe-based 
mural imaging of the bile duct. Encouraging data have been reported in small series, but they still remain largely experimental emerging mainly from expert centers, while data on PSC are scarce or non-existent. Accordingly, the recent guidelines from the Endoscopic Society for Gastrointestinal Endoscopy (ESGE) and the European Association for the Study of the Liver (EASL) do not recommend the use of these techniques in routine PSC work. ${ }^{9}$

The abovementioned techniques have mainly been used for the evaluation of indeterminate strictures. EUS is excellent for suspected stone disease and suspected ampullary tumors. However, in a small study from Australia, EUS with fine needle aspiration was also able to accurately characterize indeterminate strictures in 23/40 patients, avoiding costly subsequent cholangioscopic procedures in almost half of the patients. ${ }^{30}$ Adding EUS sampling to ERCP tissue acquisition may also be of value, particularly if a mass lesion is observed. ${ }^{31}$

IDUS has been in use for a long time but it has not gained widespread popularity. Despite this, a potential role for IDUS in the difficult distinction between PSC and IgG4-related disease has been suggested. ${ }^{32}$ With regard to CLE and OCT, these are both methods in development, in terms of technology, as well the interpretation and classification of images. ${ }^{33-36} \mathrm{Com}-$ bining CLE with cholangioscopic sampling may represent a way to speed up stricture characterization. ${ }^{37}$ Rapid improvement in computer-based imaging in general is likely to improve the output of these methods in the future, ${ }^{35}$ although the cost remains a concern.

\section{BILIARY TREATMENT}

\section{Dominant strictures}

Dominant strictures (DS) play a considerable role in the decision making in PSC patients. Traditionally, DS have been defined as "stenosis of the common bile duct with a diameter of $\leq 1.5 \mathrm{~mm}$ and/or stenosis of the hepatic duct with a diameter of $\leq 1.0 \mathrm{~mm}^{\mathrm{m} .{ }^{38}}$ In a Scandinavian prospective study with a 10-year follow-up, extrahepatic and intrahepatic DS were seen in $24 \%$ and $18 \%$ of the patients, respectively. ${ }^{39}$ In another study from the UK with a mean follow-up period of 10 years, 63\% of the patients presented with DS. ${ }^{40}$ The variability of these estimates demonstrates the difficulties with the current DS definition. Moreover, the definition fails to take into consideration the upstream and downstream caliber of the ducts, and also the role of biochemical or clinical consequences of documented DS.

DS are associated with worse outcomes, partly via the complications of obstruction, particularly septic cholangitis, partly via their strong association with the development of CCA. ${ }^{40}$
Consequently, both diagnostic and therapeutic measures are taken when DS are diagnosed. The management of DS is the primary role of ERCP in PSC patients. The short term benefits of stricture therapy in relieving obstruction and improving biochemistry are well documented, although the long-term consequences in terms of (transplantation free) survival remain somewhat obscure. No randomized trial will ever be conducted to answer this question, and model-based comparisons indicating a survival benefit ${ }^{41}$ are debatable. ${ }^{42}$ Intermittent major episodes of obstruction and inflammation contribute further to deterioration of liver function and hasten the time to cirrhosis. Some centers have proposed scheduled, prophylactic dilation of DS to prevent complications. In one major study, 268 patients with DS were offered either scheduled ERCP and dilatation, or procedures based on clinical symptoms. In this study, 51\% of scheduled ERCP patients were transplant-free at 5 years, compared to $29 \%$ in the clinically indicated ERCP group. ${ }^{43}$ Nevertheless, most centers do not offer scheduled procedures at this stage.

The main modalities for endoscopic therapy of DS are balloon dilation and plastic stents. Both have been shown to be effective, but standardization of the methods (caliber, time, repetition) is still lacking, although short-term stenting is likely preferable to long-term. ${ }^{38}$ Comparative trials are also lacking; a recent randomized controlled trial showed comparable efficacy between the two, but it was prematurely discontinued due to an unacceptable risk of adverse events in the stent arm, particularly pancreatitis and cholangitis. ${ }^{44}$ Since the number of subjects was small and adverse events surprisingly frequent, more data are needed to verify this finding. However, the current tendency in practice is to initiate therapy with balloon dilation, and to move to short-term stenting only in cases of early recurrence.

Fully covered self-expanding metal stents (C-SEMS) are increasingly utilized in the therapy of benign biliary strictures in general. Their use in PSC is so far limited, and although smaller caliber or otherwise adapted stents may change this, their main utility of longer patency may not be a critical factor in PSC patients. Currently, their main role is likely in the handling of post-transplant complications, and in the palliation of malignant duct obstruction.

\section{Adverse events}

There is a general agreement that complications from ERCP are more common in PSC patients. Although a number of large series failed to document such an increase in risk, ${ }^{45-47}$ the recent European guidelines still conclude that such a risk exists. ${ }^{9}$ Accordingly, most countries centralize the endoscopic procedures in PSC patients to specialized centers of competence. Sphincterotomy has been reported to add to the risk, 
but it should be considered that the majority of these patients will return for repeat procedures, and in that setting, a previous sphincteromy (for easier access) was shown to be protective. ${ }^{45}$ In our practice, we tend to perform sphincterotomy in PSC patients where cannulation is considered difficult, in order to prevent traumatic ampullary inflammation resulting in obstruction. It is generally recommended to give prophylactic antibiotics for all ERCP procedures in PSC patients, aligned with the idea of incomplete drainage of the bile ducts being expected in this condition. Otherwise, general measures to reduce the risk of pancreatitis (rectal non-steroidal, anti-inflammatory drugs and pancreatic stents) remain the standard of care for PSC patients.

Finally, it should be mentioned that the development of cirrhosis probably adds to the overall risk of complications. In a recent report from India on ERCP in cirrhotic patients, a MELD score $>18$ or Child-Pugh class $\mathrm{C}$ were independent risk factors, with an overall mortality of $8.5 \%$ from ERCP. ${ }^{48}$

\section{Endoscopy for post-transplant complications}

Given the substantial lifetime need for a liver transplant, post-transplant care for PSC patients represents a significant component of the endoscopic efforts. Similar to transplants for other causes early on, handling of anastomotic leaks and ischemic strictures represents the majority of early challenges. Later, it is primarily anastomotic concerns that mandate endoscopic interventions. Anastomotic strictures can be dilated or stented, while wide anastomotic orifices may be documented endoscopically but may need surgical revision if ascending infections becomes a concern. In PSC patients, the frequent use of Roux-Y reconstruction represents additional complexity of the ERCP procedures, but the introduction of device-assisted enteroscopy allows endoscopic handling of the majority of these cases. ${ }^{49}$ Access to the biliary anastomosis may be difficult by routine endoscopy, requiring single or double-balloon assistance. In addition, the surgical notes should be available where possible to better delineate the altered anatomy, and to better predict the position of the bilioenteric anastomosis. Balloon dilation of anastomotic strictures, plastic stenting in select cases, and even C-SEMS are sometimes mandated, given a sufficient length of the donor common hepatic duct to allow anchoring of the stent. These patients are often referred back to the transplant center, where the strategy selection should be a multidisciplinary discussion between the surgeon, radiologist, hepatologist, and the endoscopist. Specifically, MRCP images may be misleading with regards to the cause of the patient's symptoms.

Recurrent PSC in the transplanted liver is a concern that may be underreported, but may be as high as $20 \%-25 \%$ within a 10 -year period. ${ }^{50}$ This is especially relevant given the young age of the disease debut. The endoscopic care of this entity is similar to that of the primary disease.

\section{OTHER ENDOSCOPIC UTILITIES}

\section{Colonoscopy}

The prevalence of IBD in PSC patients varies, but reaches $80 \%$ in some countries in Northern Europe. ${ }^{51}$ The particular phenotype of PSC-IBD mandates special caution and care. Firstly, the risk of cancer development is substantially higher than in regular ulcerative colitis, despite the disease often being completely asymptomatic, at least at the time of detection. In a large Dutch study, the risk of IBD-associated colorectal cancer was increased 10-fold compared to non-PSC-associated IBD. ${ }^{4}$ Also, the time to cancer development appears to be shorter, and often with an unknown period of disease at the time of diagnosis. Thus, complete ileocolonoscopy is mandatory at time of making the PSC diagnosis, especially since rectal sparing and right-sided preponderance are commonly found. ${ }^{9}$ If no colitis is found, repeat colonoscopy is recommended at 5 -yearly intervals. If even mild colitis is found, annual surveillance is recommended with targeted and/or segmental biopsies.

Handling of polyps or dysplasia follows the general guidelines for general long-term surveillance of ulcerative colitis: isolated adenomas within normal mucosa are resected as other adenomas, while verified dysplasia in flat mucosa indicates a field effect which often mandates colectomy to remove foci of malignancy.

Finally, after liver transplantation, surveillance needs to be maintained. In a large Scandinavian study of transplanted PSC patients with up to 25 years follow-up, $25 \%$ of the patients developed colorectal neoplasia, with a hazard ratio of 4.2 of developing neoplasia after transplantation, as opposed to before. ${ }^{52}$

\section{Upper gastrointestinal endoscopy for portal hypertension complications}

Advanced PSC results in portal hypertension and cirrhosis, leading to the development of gastro-esophageal varices. Bleeding from varices is a common complication that can precede decompensated or clinically apparent cirrhosis. With regards to surveillance endoscopy, a Mayo risk score above 0.86 or an elevated aspartate/alanine aminotransferase ratio has been shown to be significantly associated with the presence of varices at initial endoscopy. ${ }^{53}$ However, for those patients being followed regularly, the same study found platelet counts below $205,000 / \mu \mathrm{L}$ and rising total bilirubin over $1.7 \mathrm{mg} / \mathrm{dL}$ were in- 
dications of disease progression and best associated with the detection of new varices. ${ }^{53}$

The Baveno VI criteria predict a low risk of varices in patients with more than $150,000 / \mu \mathrm{L}$ blood and with liver stiffness measurements below $20 \mathrm{kPa}$; thus, it is considered safe to not perform variceal surveillance endoscopy in this group. ${ }^{54}$ Radiological evaluation of liver stiffness can be significantly affected by acute inflammation, and as a result, liver stiffness readings need to take into account the clinical context. As MRCP is often performed in patients with PSC for surveillance or assessment, the use of concomitant magnetic resonance elastography is a convenient option. Indeed, global liver stiffness by magnetic resonance has been correlate well with evidence of portal hypertension and varices. ${ }^{55}$

For centers without easy access to liver fibrosis measurement, a platelet count cut off of 150,000 $\mu \mathrm{l} / \mathrm{L}$ has been clinically validated in cholestatic liver diseases, and provides a simple, non-invasive indication of liver disease progression in PSC warranting surveillance endoscopy. ${ }^{56,57}$

The indications for variceal therapy, and the considerations of methods, follow-up, and concomitant/alternative pharmacotherapy with beta-blockers are identical to liver cirrhosis with portal hypertension from other etiologies.

\section{FUTURE ROLE OF ENDOSCOPY IN PSC}

The risks and other challenges of ERCP mandate optimization of its use both in general, and also in PSC patients. Therapy in DS will likely persist, but more data on stenting versus balloon dilation, as well as specifics within both methods (calibers, time, intervals, combination therapy) are required. Furthermore, the development of other therapeutic modalities is promising. Radio frequency ablation is gaining popularity for the treatment of malignant strictures and may prove helpful even in benign disease, possibly with novel improvements like combination with laser diffuser instruments. ${ }^{58}$ After 20 years of stents and balloons, innovation in therapeutic endoscopy for management of this difficult disease is needed. In addition, developments in ancillary investigations are improving outcomes, and ERCP-based tissue sampling gives endoscopy a unique opportunity to play a substantial role in translational medicine. Improved analyses of brush material and better intraductal biopsies will help to improve clinical decision making, while identification of tumor markers in bile may support our diagnostic matrix in the future. ${ }^{59,60} \mathrm{ERCP}$ in these patients will remain challenging and should be increasingly centralized to transplant or other high-competence centers with high volumes of PSC patients.

\section{CONCLUSIONS}

Endoscopy plays a central and active role in the management of patients with PSC and has the potential to delay disease progression, reduce and relieve duct obstruction, diagnose and treat biliary malignancies, and manage post-transplant complications. These patients have a high risk of biliary, hepatic, and colonic malignancies that warrant surveillance by endoscopic and other imaging modalities. The multi-system nature of PSC requires a wholistic approach to patient care with endoscopy as a central part of this approach.

\section{Conflicts of Interest}

The authors have no potential conflicts of interest.

Funding
None.
ORCID
$\begin{array}{ll}\text { Purnima Bhat: } & \text { https://orcid.org/0000-0002-2980-0584 } \\ \text { Lars Aabakken: } & \text { https://orcid.org/0000-0002-3622-3826 }\end{array}$

\section{REFERENCES}

1. Hirschfield GM, Karlsen TH, Lindor KD, Adams DH. Primary sclerosing cholangitis. Lancet 2013;382:1587-1599.

2. Andersen IM, Fosby B, Boberg KM, et al. Indications and outcomes in liver transplantation in patients with primary sclerosing cholangitis in Norway. Transplant Direct 2015;1:e39.

3. Schrumpf E, Boberg KM, Karlsen TH. Primary sclerosing cholangitis the Norwegian experience. Scand J Gastroenterol 2015;50:781-796.

4. Boonstra K, Weersma RK, van Erpecum KJ, et al. Population-based epidemiology, malignancy risk, and outcome of primary sclerosing cholangitis. Hepatology 2013;58:2045-2055.

5. Dave M, Elmunzer BJ, Dwamena BA, Higgins PD. Primary sclerosing cholangitis: meta-analysis of diagnostic performance of MR cholangiopancreatography. Radiology 2010;256:387-396.

6. Ponsioen CY, Vrouenraets SM, Prawirodirdjo W, et al. Natural history of primary sclerosing cholangitis and prognostic value of cholangiography in a Dutch population. Gut 2002;51:562-566.

7. Ponsioen CY, Reitsma JB, Boberg KM, Aabakken L, Rauws EA, Schrumpf E. Validation of a cholangiographic prognostic model in primary sclerosing cholangitis. Endoscopy 2010;42:742-747.

8. Berstad AE, Aabakken L, Smith HJ, Aasen S, Boberg KM, Schrumpf E. Diagnostic accuracy of magnetic resonance and endoscopic retrograde cholangiography in primary sclerosing cholangitis. Clin Gastroenterol Hepatol 2006;4:514-520.

9. European Society of Gastrointestinal Endoscopy; European Association for the Study of the Liver; European Association for the Study of the Liver. Role of endoscopy in primary sclerosing cholangitis: European Society of Gastrointestinal Endoscopy (ESGE) and European Association for the Study of the Liver (EASL) clinical guideline. J Hepatol 2017;66:12651281.

10. Schramm C, Eaton J, Ringe KI, Venkatesh S, Yamamura J. Recommendations on the use of magnetic resonance imaging in PSC-A position statement from the International PSC study group. Hepatology 2017;66:1675-1688. 
11. Naess S, Björnsson E, Anmarkrud JA, et al. Small duct primary sclerosing cholangitis without inflammatory bowel disease is genetically different from large duct disease. Liver Int 2014;34:1488-1495.

12. Boberg KM, Bergquist A, Mitchell S, et al. Cholangiocarcinoma in primary sclerosing cholangitis: risk factors and clinical presentation. Scand J Gastroenterol 2002;37:1205-1211.

13. Bergquist A, Ekbom A, Olsson R, et al. Hepatic and extrahepatic malignancies in primary sclerosing cholangitis. J Hepatol 2002;36:321-327.

14. Chapman R, Fevery J, Kalloo A, et al. Diagnosis and management of primary sclerosing cholangitis. Hepatology 2010;51:660-678.

15. Kaura K, Sawas T, Bazerbachi F, et al. Cholangioscopy biopsies improve detection of cholangiocarcinoma when combined with cytology and FISH, but not in patients with PSC. Dig Dis Sci 2020;65:1471-1478.

16. Boberg KM, Jebsen P, Clausen OP, Foss A, Aabakken L, Schrumpf E. Diagnostic benefit of biliary brush cytology in cholangiocarcinoma in primary sclerosing cholangitis. J Hepatol 2006;45:568-574.

17. Hayakawa C, Hoshikawa M, Imura J, Ueno T, Koike J. Bile cytology: a new scoring system for improving diagnostic accuracy. Diagn Cytopathol 2019;47:641-647.

18. Lewis JT, Talwalkar JA, Rosen CB, Smyrk TC, Abraham SC. Precancerous bile duct pathology in end-stage primary sclerosing cholangitis, with and without cholangiocarcinoma. Am J Surg Pathol 2010;34:27-34.

19. Boyd S, Vannas M, Jokelainen K, et al. Suspicious brush cytology is an indication for liver transplantation evaluation in primary sclerosing cholangitis. World J Gastroenterol 2017;23:6147-6154.

20. von Seth E, Ouchterlony H, Dobra K, et al. Diagnostic performance of a stepwise cytological algorithm for biliary malignancy in primary sclerosing cholangitis. Liver Int 2019;39:382-388.

21. Quinn KP, Tabibian JH, Lindor KD. Clinical implications of serial versus isolated biliary fluorescence in situ hybridization (FISH) polysomy in primary sclerosing cholangitis. Scand J Gastroenterol 2017;52:377-381.

22. Singhi AD, Nikiforova MN, Chennat J, et al. Integrating next-generation sequencing to endoscopic retrograde cholangiopancreatography (ER$\mathrm{CP})$-obtained biliary specimens improves the detection and management of patients with malignant bile duct strictures. Gut 2020;69:52-61.

23. Chen WM, Wei KL, Chen YS, et al. Transpapillary biliary biopsy for malignant biliary strictures: comparison between cholangiocarcinoma and pancreatic cancer. World J Surg Oncol 2016;14:140.

24. Navaneethan U, Njei B, Lourdusamy V, Konjeti R, Vargo JJ, Parsi MA. Comparative effectiveness of biliary brush cytology and intraductal biopsy for detection of malignant biliary strictures: a systematic review and meta-analysis. Gastrointest Endosc 2015;81:168-176.

25. Chen YK, Pleskow DK. SpyGlass single-operator peroral cholangiopancreatoscopy system for the diagnosis and therapy of bile-duct disorders: a clinical feasibility study (with video). Gastrointest Endosc 2007;65:832841 .

26. Navaneethan U, Hasan MK, Kommaraju K, et al. Digital, single-operator cholangiopancreatoscopy in the diagnosis and management of pancreatobiliary disorders: a multicenter clinical experience (with video). Gastrointest Endosc 2016;84:649-655.

27. Majeed A, Castedal M, Arnelo U, Söderdahl G, Bergquist A, Said K. Optimizing the detection of biliary dysplasia in primary sclerosing cholangitis before liver transplantation. Scand J Gastroenterol 2018;53:56-63.

28. Prat F, Leblanc S, Foissac F, et al. Impact of peroral cholangioscopy on the management of indeterminate biliary conditions: a multicentre prospective trial. Frontline Gastroenterol 2019;10:236-243.

29. de Vries AB, van der Heide F, Ter Steege RWF, et al. Limited diagnostic accuracy and clinical impact of single-operator peroral cholangioscopy for indeterminate biliary strictures. Endoscopy 2020;52:107-114.

30. Nguyen NQ, Schoeman MN, Ruszkiewicz A. Clinical utility of EUS before cholangioscopy in the evaluation of difficult biliary strictures. Gastrointest Endosc 2013;78:868-874.

31. Yeo SJ, Cho CM, Jung MK, Seo AN, Bae HI. Comparison of the diagnostic performances of same-session endoscopic ultrasound- and en- doscopic retrograde cholangiopancreatography-guided tissue sampling for suspected biliary strictures at different primary tumor sites. Korean J Gastroenterol 2019;73:213-218.

32. Naitoh I, Nakazawa T, Hayashi K, et al. Comparison of intraductal ultrasonography findings between primary sclerosing cholangitis and IgG4-related sclerosing cholangitis. J Gastroenterol Hepatol 2015;30:1104-1109.

33. Dubow M, Tatman PD, Shah RJ. Individual probe based confocal laser endomicroscopy criteria in the analysis of indeterminate biliary strictures. Scand J Gastroenterol 2018;53:1358-1363.

34. Rizvi S, Eaton J, Yang JD, Chandrasekhara V, Gores GJ. Emerging technologies for the diagnosis of perihilar cholangiocarcinoma. Semin Liver Dis 2018;38:160-169.

35. Tyberg A, Xu MM, Gaidhane M, Kahaleh M. Second generation optical coherence tomography: preliminary experience in pancreatic and biliary strictures. Dig Liver Dis 2018;50:1214-1217.

36. Caillol F, Bories E, Autret A, et al. Evaluation of pCLE in the bile duct: final results of EMID study : pCLE: impact in the management of bile duct strictures. Surg Endosc 2015;29:2661-2668.

37. Yang JF, Sharaiha RZ, Francis G, et al. Diagnostic accuracy of directed cholangioscopic biopsies and confocal laser endomicroscopy in cytology-negative indeterminate bile duct stricture: a multicenter comparison trial. Minerva Gastroenterol Dietol 2016;62:227-233.

38. Ponsioen CY, Lam K, van Milligen de Wit AW, Huibregtse K, Tytgat GN. Four years experience with short term stenting in primary sclerosing cholangitis. Am J Gastroenterol 1999;94:2403-2407.

39. Björnsson E, Lindqvist-Ottosson J, Asztely M, Olsson R. Dominant strictures in patients with primary sclerosing cholangitis. Am J Gastroenterol 2004;99:502-508.

40. Chapman MH, Webster GJ, Bannoo S, Johnson GJ, Wittmann J, Pereira SP. Cholangiocarcinoma and dominant strictures in patients with primary sclerosing cholangitis: a 25-year single-centre experience. Eur J Gastroenterol Hepatol 2012;24:1051-1058.

41. Stiehl A, Rudolph G, Klöters-Plachky P, Sauer P, Walker S. Development of dominant bile duct stenoses in patients with primary sclerosing cholangitis treated with ursodeoxycholic acid: outcome after endoscopic treatment. J Hepatol 2002;36:151-156.

42. Tabibian JH, Baron TH. Endoscopic management of primary sclerosing cholangitis. Expert Rev Gastroenterol Hepatol 2018;12:693-703.

43. Rupp C, Hippchen T, Bruckner T, et al. Effect of scheduled endoscopic dilatation of dominant strictures on outcome in patients with primary sclerosing cholangitis. Gut 2019;68:2170-2178.

44. Ponsioen CY, Arnelo U, Bergquist A, et al. No superiority of stents vs balloon dilatation for dominant strictures in patients with primary sclerosing cholangitis. Gastroenterology 2018;155:752-759.e5.

45. Ismail S, Kylänpää L, Mustonen H, et al. Risk factors for complications of ERCP in primary sclerosing cholangitis. Endoscopy 2012;44:11331138.

46. Navaneethan U, Jegadeesan R, Nayak S, et al. ERCP-related adverse events in patients with primary sclerosing cholangitis. Gastrointest Endosc 2015;81:410-419.

47. Etzel JP, Eng SC, Ko CW, et al. Complications after ERCP in patients with primary sclerosing cholangitis. Gastrointest Endosc 2008;67:643648.

48. Jagtap N, Nabi Z, Tandan M, et al. Is it safe to perform endoscopic retrograde cholangiopancreatography in decompensated cirrhosis? J Clin Exp Hepatol 2019;9:554-560.

49. Aabakken L, Bretthauer M, Line PD. Double-balloon enteroscopy for endoscopic retrograde cholangiography in patients with a Roux-en-Y anastomosis. Endoscopy 2007;39:1068-1071.

50. Montano-Loza AJ, Bhanji RA, Wasilenko S, Mason AL. Systematic review: recurrent autoimmune liver diseases after liver transplantation. Aliment Pharmacol Ther 2017;45:485-500.

51. Broome U, Bergquist A. Primary sclerosing cholangitis, inflammatory 
bowel disease, and colon cancer. Semin Liver Dis 2006;26:31-41.

52. Jørgensen KK, Lindström L, Cvancarova M, et al. Colorectal neoplasia in patients with primary sclerosing cholangitis undergoing liver transplantation: a Nordic multicenter study. Scand J Gastroenterol 2012;47:10211029.

53. Treeprasertsuk S, Kowdley KV, Luketic VA, et al. The predictors of the presence of varices in patients with primary sclerosing cholangitis. Hepatology 2010;51:1302-1310.

54. Cardenas A, Mendez-Bocanegra A. Report of the Baveno VI consensus workshop. Ann Hepatol 2016;15:289-290.

55. Bookwalter CA, Venkatesh SK, Eaton JE, Smyrk TD, Ehman RL. MR elastography in primary sclerosing cholangitis: correlating liver stiffness with bile duct strictures and parenchymal changes. Abdom Radiol (NY) 2018;43:3260-3270.

56. Tse Y, Narula N, Uhanova J, Sirpal S, Marotta P, Chandok N. When to perform gastroscopy in the PSC patient. Ann Hepatol 2016;15:135-136.

57. Moctezuma-Velazquez C, Saffioti F, Tasayco-Huaman S, et al. Non-invasive prediction of high-risk varices in patients with primary biliary cholangitis and primary sclerosing cholangitis. Am J Gastroenterol 2019;114:446-452.

58. Park JS, Jeong S, Lee DH, Kim JM, Kim SM, Kang HW. The use of a 532-nm laser fitted with a balloon and a cylindrical light diffuser to treat benign biliary stricture: a pilot study. Lasers Med Sci 2020 Mar 10 [Epub]. https://doi.org/10.1007/s10103-020-02992-6.

59. Ren H, Luo M, Chen J, et al. Identification of TPD52 and DNAJB1 as two novel bile biomarkers for cholangiocarcinoma by iTRAQbased quantitative proteomics analysis. Oncol Rep 2019;42:2622-2634.

60. Voigtländer T, Metzger J, Husi H, et al. Bile and urine peptide marker profiles: access keys to molecular pathways and biological processes in cholangiocarcinoma. J Biomed Sci 2020;27:13. 